Station of the South African Broadcasting Corporation at Panorama.

Under "Time Services", reference is made to improvements to the control circuits of the Diesel generator and to the vibrator power supply units so that the quartz clock installation is now practically independent of mains interruptions. A new frequency divider employing cold-cathode valves was built, and the stability of other frequency dividers improved. The performance of the ring crystal over short periods was rather more erratic than had been expected, and from Oetober onwards all the time and frequency equipment has been controlled by oscillator $4 A$ while further tests are being made. A twelve-channel frequency recorder, designed and built by the British Post Office, was delivered in June, and this recorder has been of very great value in keeping a continuous check on the performance of all parts of the time installation. A new cathode-ray oscilloscope comparison unit was built and this measures the reception time of time signals in terms of local time to one ten-thousandth of a second.

Under "Miscellaneous Public Services" reference is made to the Wiechert horizontal seismograph which was in operation throughout the year; local earth tremors and records of ten distant earthquakes; and records of rain have been sent monthly to the Bernard Price Institute for inclusion in its monthly Seismological Bulletin. Reference is also made to the installation of a synchronous motor drive on the twin telescope, and to the transfer of the Leyden Southern Station from Johannesburg to Hartbeestport.

\title{
FEDERAL RESEARCH AND DEVELOPMENT EXPENDITURE IN THE UNITED STATES*
}

$\mathrm{T}$ HE National Science Foundation has issued an analysis of the Federal Research and Development Budget for the fiscal years 1956,1957 and 1958 , in which latter year twenty-three agencies of the Federal Government allocated 3,400 million dollars for scientific research and development, an increase of nearly one-fourth on 1956. Actual expenditure increased from about 2,500 million dollars to almost 3,000 million dollars in 1957 and is expected to reach 3,300 million dollars in 1958 . From 85 to 90 per cent of these funds are for the conduct of research and development, including the pay and allowances of personnel, actual expenditure increasing by 14 per cent in 1957, and it is expected to increase by 10 per cent in 1958 to 2,900 million dollars. Some 10 15 per cent of the total is on the expansion of plant and equipment, including the acquisition of land, and expenditure for these purposes increased from just over 200 million dollars in 1956 to an estimated 437 million dollars in 1958, mainly on plant or facilities for defence.

Of the twenty-three agencies, the Department of Defense and the Atomic Energy Commission together account for 88,85 and 82 per cent of the total funds in 1956,1957 and 1958, respectively, about 45 per cent of the Defense Department funds being administered by the Air Force. For 1957 and 1958, 672 million dollars were allocated by the Atomic Energy Commission, compared with 2,166 million and 2,11I million dollars, respectively, by the Defense Department. Allocations of the Department of Health, Education and Welfare for scientific research and development increased from 89 million dollars in 1956 to 200 million in 1958 , and of the 182 million allocated in 1957,175 million were primarily by the National Institutes of Health for research on the diagnosis, cause and treatment of disease. The Department of Agriculture increased its allocation from 84 million dollars in 1956 to 108 million in 1957 and 132 million dollars in 1958 ; for the National Advisory Committee for Aeronautics, the corresponding figures are 66 million, 80 million and 94 million dollars; for the Department of the Interior, 38 million, 47 million and 53 million dollars; for the National Science Foundation, 17 million, 48 * National Science Foundation. Federal Funds for Science 6 : 1957 and 1958. Pp. ili +60 . (Washington, D.C.: Governmen Printing Office, 1957.) 40 cents. million and 47 million dollars; and for the Depart. ment of Commerce, 18 million, 25 million and 33 million dollars, respectively, the decrease for 1958 in the allocation by the National Science Foundation being because of the International Geophysical Year.

Of the 2,231 million dollars expended on the conduct of research and development in 1956, 1,388 million was on development and 844 million on research, of which 157 million was on basic research. The corresponding figures for 1957 are estimated as 2,635 million dollars, 1,671 million, 964 million and 218 million, respectively, and for $1958,2,782$ million dollars, 1761 million, 1,021 million and 233 million, respectively. Of the expenditure on research in 1956, 198 million dollars was on the biological sciences, 616 million dollars on the physical sciences, and 30 million on the social sciences ; in basic research, the corresponding distribution was 50 million, 104 million and 3 million dollars. For 1957 the corresponding distribution in total research is estimated as 281 million, 627 million and 35 million, and in basic research 70 million, 143 million and 4 million dollars; and for 1958 in total research, 317 million, 637 million and 48 million, and in basic research, 83 million, 143 million and 6 million dollars. Subdivided again, total research expenditure on the biological sciences in 1956 included 99 million dollars on medical sciences and 44 million on agricultural sciences; for 1957 the corresponding estimates are 158 million and 53 million dollars, and for 1958 , 177 million and 59 million dollars. That on the physical sciences in 1956 included 6 million dollars on the mathematical sciences and $\mathbf{4 5 6}$ million dollars on the engineering sciences; corresponding estimates for 1957 are 7 million and 435 million dollars, respectively.

Of the 2,830 million dollars allocated for the conduct of research and development by the Federal Government in 1957, 48 per cent was spent on work performed by Government agencies, including pay and allowances of military personnel engaged in such work. Of the remainder, 35 per cent went to work carried out by profit organizations, about one-fourth of this going to research institutions administered by such organizations, 14 per cent went to educational institutions and the remaining 3 per cent to other institutions, including non-profit research institutions, foundations and hospitals. 
Since the 1948 low level of just over 850 million dollars, Federal Government expenditure on scientific research and development has risen steadily, except in 1954, to 2,800 million dollars in 1957 , or just over 4 per cent of the total budget expenditure compared with just over 2 per cent, and it is estimated that expenditure on basic research has increased by more than 85 per cent since 1952, although still amounting to only $\mathbf{8}$ per cent of the total funds for the conduct of research and development, exclusive of the pay and allowances of military personnel. In the same period, allocations for research in the biological sciences also increased by more than 83 per cent. It is estimated that the increases have been greater than the rate of increase in costs for salaries and equipment for scientific work and that accordingly when due account is taken of such rising costs the long-term trend still reflects a steady increase in the provision of Government funds for scientific research and development. Besides the statistical tables, the report includes technical notes on the limitations of the data and definitions and a list of research centres.

\section{PHOTOPERIODISM IN PLANTS AND ANIMALS}

A $\mathrm{N}$ international symposium on "Photoperiodism A in Plants and Animals", sponsored by the Photobiology Committee of the National Research Council of the United States, was held at Gatlinburg, Tennessee, during October 29-November 2.

In an introductory session the reversible photochemical properties of certain dyes were described by Dr. G. Oster (Polytechnic Institute of Brooklyn) and problems of energy transfer in photochemical systems were discussed by Dr. Gordon Tollin (University of California, Berkeley). Dr. Stacey French (Carnegie Institution, Stanford) discussed the difficulties of determining action and absorption spectra in living systems.

One session was devoted to the various photoperiodic effects observed in growth and dormancy of plants. Dr. J. L. Liverman (Texas Agricultural Experiment Station) and Dr. W. H. Klein (Smithsonian Institution, Washington) dealt with the interaction between red light and various other factors in the growth of bean leaf disks, and the uncoiling of the bean epicotyl hook, respectively. Both speakers reported that the effects of indole-acetic acid, kinetin, gibberellic acid and the cobaltous ion seem to be independent of those of red light. -There appears, however, to be an interaction between adenine and red light in the growth of bean leaf disks. Dr. E. H. Toole (U.S. Dept. of Agriculture, Beltsville) described the responses of various light-sensitive seeds and Dr. P. F. Wareing (University of Manchester) dealt with the photoperiodic control of germination, with special reference to the action of various spectral regions and the possible role of growth inhibitors. Dr. R. J. Downs (Ũ.S. Dept. of Agriculture, Beltsville) discussed the interaction between red and infra-red radiation in relation to various aspects of vegetative growth. The effects of red irradiation on the activity of indole-acetic acid oxidase were shown by Dr. A. W. Galston (Yale University) to be due to the formation of an inhibitor of this enzyme by red light.

Dr. R. van den Veen (Philips' Research Laboratories, Eindhoven) described experiments which involved growing various species entirely under high-intensity monochromatic light. It was found that there are marked differences between species with respect to growth responses, under the various spectral regions. There are complex interactions between blue and red, especially in relation to the control of flowering. Prof. E. C. Wassink (Agricultural University, Wageningen) also described the responses of various species grown under high-intensity radiation in narrow spectral regions.

Two sessions were devoted to the photoperiodic control of flowering. Dr. Ralph Wetmore (Harvard
University) and Dr. E. M. Gifford (University of California, Davis) described the structural changes occurring in shoot-apices of Xanthium and other species in the transition from the vegetative to the flowering condition. The interaction of red and farred radiation in the flowering of various species, including Hyoscyamus, was dealt with by Dr. H. A. Borthwick (U.S. Dept. of Agriculture, Beltsville). Dr. Roy Sachs (University of California, Los Angeles) discussed the implications of 'long-short' day plants, such as Cestrum nocturnum, for general theories of photoperiodism.

Dr. A. Lang (University of California, Los Angeles) read a paper dealing with the general problem of the role of auxin and gibberellins in flowering. Auxin tends to be inhibitory of flowering in short-day plants and promotive in long-day plants, but it appears only to modify the responses. Both gibberellic acid and gibberellin-like fractions from Cucurbita endosperm are capable of inducing flowering in some long-day plants, but cannot replace photo-induction in short-day plants. Photo-induction in long-day plants appears to involve reactions other than gibberellin-controlled processes, which may be concerned primarily with stem elongation. The interactions between gibberellic acid and photoperiodic responses were discussed by Prof. Fausto Lona (University of Parma) for a wide variety of species.

The effects of certain synthetic hormones on flowering of Xanthium were described by Dr. A. Naylor (Duke University), and Dr. F. Salisbury (Colorado State University) described the interaction between various applied growth substances and the critical dark period in Xanthium. Dr. W. Jacobs (Princeton University) discussed the relations between auxin, day-length and compensatory growth in Coleus.

In a general paper on the nature of the photoinductive processes in photoperiodism, Dr. James Bonner (Califormia Institute of Technology) outlined the present state of knowledge of the various partial processes involved, and discussed the possible reasons why the 'flower-hormone' has not yet been isolated. Dr. R. B. Withrow (Smithsonian Institution, Washington) gave a general account of the kinetic aspects of the photoreactions. He distinguished between 'graded' responses (for example, of light-sensitive seeds) and 'threshold' responses (for example, photoperiodic phenomena). Dr. S. B. Hendricks (U.S. Dept. of Agriculture, Beltsville) also deslt with kinetic aspects of the photo-reactions of photoperiodism and showed how certain kinetic parameters of the photoreceptor system can be derived. He also described a second photo-receptor system which appears to be involved in anthocyanin synthesis. 